\title{
Outbreak
}

\section{An outbreak of Serratia liquefaciens at a rural health center in The Gambia}

\author{
Usman Nurudeen Ikumapayi, Abdoulie Kanteh, Jarra Manneh, Modou Lamin, Grant Austin Mackenzie \\ Department for Disease Control and Elimination, Medical Research Council Unit, Fajara, Gambia
}

\begin{abstract}
Introduction: Healthcare-associated infections (HAIs) are better documented in developed than in developing countries. There are emerging reports regarding the high frequency of HAIs in developing countries. We aimed to report an outbreak of an HAI caused by Serratia liquefaciens at a rural health center in The Gambia.

Methodology: Following an abrupt increase in the isolation of S. liquefaciens in clinical samples, laboratory and clinical consumables, as well as staff, were screened for contamination with S. liquefaciens. Conventional microbiological techniques and biochemical identification tests were used. A phenotypic typing was achieved using the Kirby-Bauer antibiotic susceptibility method. Strategies to control the outbreak were implemented.

Results: A total of 794 samples were processed during the outbreak; 44 (6\%) grew S. liquefaciens. Five (25\%) of the 20 suspected contaminated materials (hospital consumables and equipment) screened yielded growth of the organism. The primary source of the outbreak was hospital consumables. Three (7\%) of the 44 infected children died with no other known cause than $S$. liquefaciens infection. Ninety-nine percent similarity of the antibiogram phenotypic typing suggests the isolates were from the same clonal origin. The outbreak was successfully controlled after the removal and sterilization of the respective contaminated fluids and equipment.

Conclusions: This HAI was caused by poor practice in the preparation of medications for nebulization and intravenous infusion, hygiene practices, and a lack of awareness among staff about infection control. We recommend further studies to delineate the role played by HAIs in the developing world.
\end{abstract}

Key words: Healthcare-associated infection; outbreak; Serratia liquefaciens; antibiotic; Gambia.

J Infect Dev Ctries 2016; 10(8):791-798. doi:10.3855/jidc.7184

(Received 23 May 2015 - Accepted 18 November 2015)

Copyright (C) 2016 Ikumapayi et al. This is an open-access article distributed under the Creative Commons Attribution License, which permits unrestricted use, distribution, and reproduction in any medium, provided the original work is properly cited.

\section{Introduction}

Healthcare-associated infections (HAIs) are considered the commonest adverse conditions threatening patients' safety worldwide [1]. The prevalence of HAIs is higher in developing countries, particularly in Africa, compared to the developed world [2-3]. HAIs cause approximately 100,000 deaths per year in developed countries such as the United States [4]. Studies have shown that contamination of health workers' protective equipment, such as gowns and gloves, with healthcare-associated pathogens is common [4-5].

The genus Serratia is one pathogen known to cause HAIs. Serratia belongs to the family Enterobacteriaceae; over time, the taxonomy of Serratia has evolved, with 14 currently described species belonging to the genus [6]. Serratia species are usually recognized as nosocomial pathogens; however, some recent studies have demonstrated that Serratia infection can be community acquired, with Serratia marcescens being implicated [7-8]. Infections with $S$. liquefaciens in healthcare setting are uncommon compared to infections with $S$. marcescens. $S$. liquefaciens colonizes hands and the respiratory, gastrointestinal, and urinary tracts [9-10]. It is a highly motile organism with swarming capacity and is commonly found in water, soil, plants, and insects [11]. The pathogenicity of $S$. liquefaciens is well established in humans, insects, and fish [11-12], and cases of fatal infection have been reported [13]. Many investigations have documented outbreaks of $S$. liquefaciens in settings of medical care, such as hemodialysis centers and neurosurgery departments [14-15]. S. liquefaciens often colonizes hospital instruments and consumable materials that include pressure monitoring equipment, suction pumps, oxygen concentrators, mechanical ventilators, intravenous infusion sets, intravascular catheters, hand-soap dispensers, and vials of liquid medication [16-17]. Transfusion reactions associated with contaminated blood products have also been documented [18-19]. In 2008, the European Centre for Disease Prevention and Control reported that Serratia species represented $2.0 \%$ of all bloodstream infections, ranking organisms from this genus as the tenth most 
commonly recovered organisms from intensive care unit (ICU)-acquired bloodstream infections [20]. A case of sepsis caused by $S$. liquefaciens following a vitamin $\mathrm{C}$ infusion has also been reported [21]. Many reports have highlighted $S$. liquefaciens in bloodstream infections, fistulous pyoderma, and infective endocarditis [22-24]. Serratia species have been isolated from specimens such as blood, urine, cerebrospinal fluid, sputum, induced sputum, lung aspirate, and wound swabs [11]. High levels of antimicrobial resistance among isolates of $S$. liquefaciens complicate treatment [13].

The aim of this report was to describe an investigation and intervention conducted to terminate an outbreak of HAI caused by $S$. liquefaciens in a rural health center in The Gambia, West Africa. Thus, we highlight the potential for such outbreaks in developing countries and the interventions that can be used to address such events.

\section{Methodology}

Study area and patient population

This study was conducted at the Basse Health Centre (BHC) in Upper River Region (URR) of eastern Gambia. The health center serves a population of over 200,000 , among whom those under five years of age account for $20 \%$ of the population. A population-based surveillance study of the burden of pneumococcal disease and a study of pneumonia etiology started in May 2008 and August 2009, respectively. The etiology study ended in March 2011, while the surveillance study is ongoing. The Medical Research Council (MRC) laboratory at the MRC Basse field station processes samples to detect pathogens for many ongoing studies that included the etiology and surveillance studies. Over 20,000 samples were processed at MRC laboratory in Basse from these two studies prior to the onset of the outbreak. The first isolate in the outbreak was identified on 30 June 2010. One isolate of $S$. marscens, and no isolates of $S$. liquefaciens were detected prior to June 2010.

\section{Description of the outbreak}

In mid-August 2010, staff at the Basse MRC laboratory became concerned about the frequent isolation of $S$. liquefaciens from clinical samples, particularly invasive samples such as blood. The first, second, and third S. liquefaciens isolates from blood were isolated 30 June, 25 July, and 1 August. Three isolates from nasopharyngeal aspirates (NPAs) were isolated on August 18 (Table 1). When the eighth isolate of $S$. liquefaciens was isolated, the laboratory conducted a thorough investigation to determine if there was a source of contamination in the laboratory. All laboratory equipment (incubators, suction tube, BACTEC 9050, class II safety cabinet, centrifuges, and fridges) and consumable reagents such as distilled water, normal saline, and prepared bacterial culture media were inoculated for microbiology bacterial growth using conventional bacterial culture on fluid and solid media. The outcome of the investigation of the laboratory sources revealed an absence of $S$. liquefaciens. When the twelfth isolate was detected, on 22 August 2010, the investigation was expanded to the clinical setting at the health center.

General investigation to establish corrective and preventive actions

Following the notification of relevant stakeholders, a committee including clinicians, microbiologist, and a nurse was formed to address the problem. The major task was to investigate and identify the source of the outbreak. First, the procedure room where intravenous infusions were prepared and administered was inspected. Also, the administration of infusion fluid, drug suspension vials, and nebulized salbutamol fluid were observed. Additionally, the committee monitored procedures for the collection of venous blood and the inoculation of blood culture bottles and sample processing in the laboratory.

All infusion fluid, liquid medication, sterilizing agents, LabGuard-hand soap, and equipment used for patient care was swabbed and cultured for bacterial

Table 1. Detection pattern for the first to sixteenth isolates of Serratia liquefaciens.

\begin{tabular}{ccccc}
\hline Case & Date & No. of Sample & Type of sample & Diagnosis \\
\hline 1 & June 30, 2010 & 1 & Blood & Pneumonia \\
2 & July 25, 2010 & 1 & Blood & Plood \\
3 & August 1, 2010 & 1 & NPA A & Pneumonia \\
$4-6$ & August 18,2010 & 3 & NPA-1, IS-1 & Pneumonia \\
$7-8$ & August 19,2010 & 2 & NPA-2, IS-1 & Pneumonia \\
$9-11$ & August 20, 2010 & 3 & Blood & Pneumonia \\
12 & August 22, 2010 & 1 & NPA-3, IS-1 & Pneumonia \\
$13-16$ & August 23, 2010 & 4 &
\end{tabular}

LA: lung aspirate; NPA: nasopharyngeal aspirate; IS: induced sputum. 
isolation and identification. In addition, the hands of staff (nurses/phlebotomist, field and laboratory personnel) attending to patients and handling and processing samples were swabbed and cultured. Antimicrobial susceptibility tests were conducted on $S$. liquefaciens isolates from contaminated items, and the results were compared with antimicrobial susceptibility results obtained from isolates from the original clinical samples for phenotypic comparison.

\section{Bacteriology}

Isolation of $S$. liquefaciens from clinical samples that included blood and lung aspirate samples was achieved by incubating inoculated blood culture bottles (BD BACTEC Peds Plus - Maryland, USA) in an automated blood culture machine (BACTEC 9050 Maryland, USA) followed by subculture on solid media (blood, chocolate, and MacConkey agars). Nasoparngeal aspirate and induced sputum samples were also cultured on the three solid agar media and incubated overnight at $37^{\circ} \mathrm{C}$. Identification of the organism was achieved using standard biochemical techniques including analytical profile index 20 nonenteric and 20 enteric (API 20NE and API 20E; BioMerieux - Macy-I'Etoile, France). Antimicrobial susceptibility testing was performed on all the isolates using the Kirby-Bauer disk diffusion method, following
Figure 1. Distribution of $S$. liquefaciens during and postoutbreak.

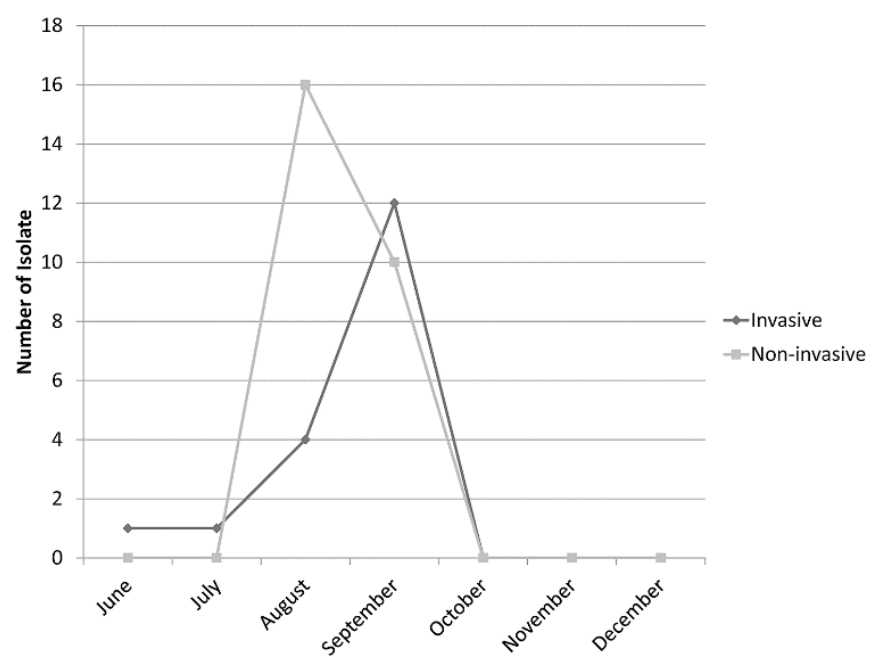

the 2010 guidelines of the Clinical and Laboratory Standards Institute (CLSI). The control organism used was Escherichia coli ATCC 25922.

\section{Results}

S. liquefaciens was isolated from 44 children during the 10 weeks (30 June-16 September 2010) of the outbreak (Figure 1). The affected children were all seen at the outpatient department. Of the 794 clinical

Table 2. Screened hospital consumables and equipment from health center outpatient department and Medical Research Council laboratory for bacterial growth.

\begin{tabular}{|c|c|c|}
\hline S/No. & Consumable and equipment & Result \\
\hline & Health Center Outpatient Department & \\
\hline 1 & Normal saline (infusion, $0.85 \%$ - in use) & S. liquefaciens $\left(>25 \times 10^{5}\right.$ organisms $\left./ \mathrm{mL}\right)$ \\
\hline 2 & Normal saline in syringe & S. liquefaciens $\left(>25 \times 10^{5}\right.$ organisms $\left./ \mathrm{mL}\right)$ \\
\hline 3 & Ventolin fluid for nebulization & S. liquefaciens $\left(>25 \times 10^{5}\right.$ organisms $\left./ \mathrm{mL}\right)$ \\
\hline 4 & Methylated spirit (in use) & S. liquefaciens $\left(>25 \times 10^{5}\right.$ organisms $\left./ \mathrm{mL}\right)$ \\
\hline 5 & Oxygen concentrator & S. liquefaciens $\left(>25 \times 10^{5}\right.$ organisms $\left./ \mathrm{mL}\right)$ \\
\hline 6 & $\begin{array}{l}\text { Normal saline (infusion, } 0.85 \% \text { - unused } \\
\text { stock) }\end{array}$ & No bacterial growth \\
\hline 7 & Methylated spirit (unused stock) & No bacterial growth \\
\hline 8 & Totacide disinfectant & No bacterial growth \\
\hline 9 & LabGuard liquid soap & No bacterial growth \\
\hline 10 & BACTEC blood culture bottle & No bacterial growth \\
\hline 11 & Conventional blood culture bottle & No bacterial growth \\
\hline 12 & Glucose (intravenous infusion) & No bacterial growth \\
\hline 13 & Benzypenicillin & No bacterial growth \\
\hline 14 & Suction tube connected to vacuum & Bacillus species $\left(<20 \times 10^{5}\right.$ organisms $\left./ \mathrm{mL}\right)$ \\
\hline \multirow[t]{2}{*}{15} & Suction tube connected to mucus extractor & $\begin{array}{l}\text { Bacillus species, Viridans streptococcus, and coagulase-negative staphylococci } \\
\left(<20 \times 10^{5} \text { organisms } / \mathrm{mL}\right)\end{array}$ \\
\hline & Basse MRC Laboratory & \\
\hline 16 & Sterile distilled water - stock and in use & No bacterial growth \\
\hline 17 & Sterile normal saline - stock and in use & No bacterial growth \\
\hline 18 & Methylated spirit & No bacterial growth \\
\hline 19 & BACTEC culture bottle top & No bacterial growth \\
\hline 20 & Conventional blood culture bottle top & Coagulase-negative staphylococci $\left(<20 \times 10^{5}\right.$ organisms $\left./ \mathrm{mL}\right)$ \\
\hline
\end{tabular}


samples processed for bacterial culture during the outbreak, $44(6 \%)$ yielded $S$. liquefaciens; these samples included blood (14; 32\%), lung aspirate (4; $9 \%)$, nasopharyngeal aspirate $(22 ; 50 \%)$, and induced sputum $(4 ; 9 \%)$. Twenty clinical items used in the collection and preparation of clinical samples were screened for bacterial growth (Table 2). Microbiological investigation of clinical materials and equipment revealed that $5 / 20(25 \%)$ were contaminated with $S$. liquefaciens, and $3 / 20 \quad(15.3 \%)$ were contaminated with other environmental bacteria, such as coagulase-negative Staphylococcus, Streptococcus viridians, and Bacillus species (Table 2). The primary sources of contamination were the saline used for preparation of intravenous medication, salbutamol fluid used to prepare solutions for nebulization, and surgical spirit used for cleansing skin before venepuncture. Repeated use of single bottles and vials for multiple patients was identified as a sub-standard practice that likely contributed to the outbreak. Eight of 15 swabs of the hands of clinical staff at the pediatric outpatient department (OPD) and laboratory staff grew coagulasenegative staphylococci. S. liquefaciens was not isolated from the hands of any staff member. Three of the 44 infected patients (7\%) died, and S. liquefaciens was isolated from the blood of the three patients who died $(3 / 18$ [17\%]) (Figure 2). Interestingly, the impact of control measures introduced was excellent in that there were no cases of $S$. liquefaciens isolated in the laboratory in October, November, and December 2010 (post-outbreak) and thereafter.

The antimicrobial susceptibility patterns of the isolates obtained from clinical samples, hospital consumables, and equipment were very similar, suggesting they were all related to one original source (Table 3), but high throughput methods such as pulsedfield gel electrophoresis (PFGE) or random amplified polymorphic DNA (RAPD) with high power discriminatory outcome were not available to determine clonal similarity.

\section{Discussion}

Healthy individuals rarely become infected by the genus Serratia, but hospitalized patients may be colonized or infected by $S$. marcescens [7,25]. Occasionally, S. liquefaciens is isolated from clinical specimens but its pathogenic role is often unclear [6]. $S$. liquefaciens causes infections in immunocompromised hosts [13], such as neonates [26], and in those with indwelling/introduced foreign bodies/liquids, e.g., intravenous/intra-arterial (IV/IA) lines, endotracheal tubes, multiple use vials [16]; thus, the entry routes are ingestion, injection, and catheterization. Our investigation of an outbreak of $S$. liquefaciens infection in a rural African health center revealed expected sources and modes of transmission; various solutions used in patient care were contaminated and there was poor practice in the use of these solutions.

Figure 2. Type of samples processed during outbreak.

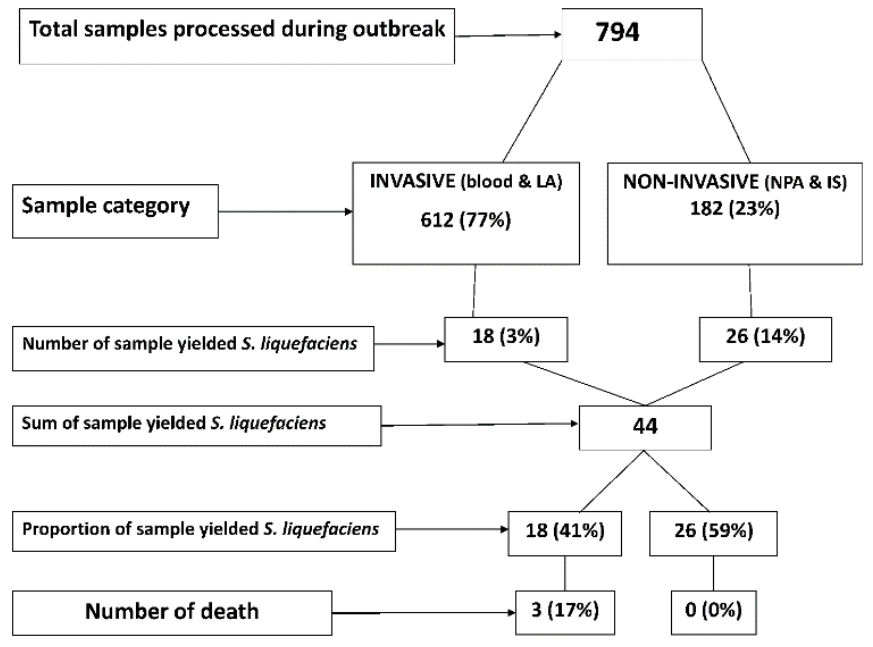

Table 3. Comparison of antibiotic susceptibility profile of the Serratia liquefaciens isolates from human $(\mathrm{n}=44)$ and contaminated health clinical materials $(n=5)$.

\begin{tabular}{lcccc}
\hline \multirow{2}{*}{$\begin{array}{l}\text { Antibiotic } \\
\text { concentration) }\end{array}$} & \multicolumn{2}{c}{ Human (invasive and non-invasive) isolates (n= } & 44) & Consumables and equipment isolates (n= 5) \\
\cline { 2 - 5 } & $\mathbf{R}(\%)$ & $\mathbf{S ~ ( \% )}$ & $\mathbf{R}(\mathbf{\%})$ & $\mathbf{S}(\mathbf{\%})$ \\
\hline Ampicillin $(10 \mu \mathrm{g})$ & $44(100)$ & $0(0)$ & $0(0)$ & $0(0)$ \\
Chloramphenicol $(30 \mu \mathrm{g})$ & $0(0)$ & $44(100)$ & $0(0)$ & $5(100)$ \\
Cotrimoxazole $(30 \mu \mathrm{g})$ & $0(0)$ & $39(89)$ & $0(0)$ & $5(100)$ \\
Tetracycline $(30 \mu \mathrm{g})$ & $5(11)$ & $44(100)$ & $0(0)$ & $5(100)$ \\
Gentamicin $(30 \mu \mathrm{g})$ & $0(0)$ & $44(100)$ & $0(0)$ & $5(100)$ \\
Ciprofloxacin $(30 \mu \mathrm{g})$ & $0(0)$ & $44(100)$ & $0(0)$ & $5(100)$ \\
Cefotaxime $(30 \mu \mathrm{g})$ & $0(0)$ & $44(100)$ & $0(0)$ & $5(100)$ \\
Nalidixic acid $(30 \mu \mathrm{g})$ & $0(0)$ & & & $5(100)$ \\
\hline
\end{tabular}

R: resistant; S: sensitive. 
Review of the three deaths recorded in this study by the attending clinician revealed that these deaths were likely attributed to infection with $S$. liquefaciens. In 2011, a study conducted in Greece made a similar fatal case report [13]. Again, our findings corroborate those of a report of a 10-year population-based study in Canberra, Australia, which showed Serratia species bacteremia to be more common than what was known, with a high proportion (47\%) of episodes [27]. Antibiogram phenotyping of isolates obtained from clinical samples, hospital consumables, and equipment showed 99\% similarity, suggesting isolates were from a common source and probably of the same clonal origin. One of the limitations of this study was the unavailability of genotypic characterizations such as PFGE or RAPD assays, which may be used to confirm clonal similarity of isolates.

In this investigation, the original source of contamination of the pediatric OPD items by $S$. liquefaciens is not clear. Nonetheless, our findings suggest that contamination happened in the pediatric OPD. The question about the source of the contamination has no straightforward answer, but it was certain that the source was neither the commercial $0.85 \%$ saline nor the methylated spirit because only the in-use quantities of these agents were contaminated and not the unused stock, with evidenced sterility of the unused stock. Our study also established that the contamination was not from the Basse MRC laboratory. Also, the contamination was not from the hands of the healthcare staff (Table 4), reinforcing the bactericidal effect of hand washing with soap (LabGuard) against microbial agents such as $S$. liquefaciens. The confirmed sources of contamination included the salbutamol fluid, single vials of which were used for nebulization of multiple patients. Oxygen concentrators were also contaminated with $S$. liquefaciens, and these machines were often shared among patients. Normal saline infusion fluid was contaminated, most likely due to multiple puncture of the bottles in order to prepare dosages of medication or volumes for resuscitation. Our hypothesis is that either an asymptomatic carrier or a symptomatic individual contaminated the inhaling fluid and the inhaling devices because there was a phenotypic similarity of the strains isolated from blood, lung aspirate, and induced sputum compared with strains from contaminated items. We also observed poor aseptic technique that most likely contributed to the contamination of the normal saline infusion and methylated spirit, as it was likely that $S$. liquefaciens was inoculated into the infusion bottle due to multiple punctures. Also, an asymptomatic carrier may have generated droplets either by coughing or sneezing during sample collection, thus inoculating uncovered disinfecting agents such as methylated spirit, which later was used to disinfect a patient's skin prior to sample collection but instead caused contamination of the skin. Contamination of methylated spirit is a strong possibility because the first three $S$. liquefaciens were first isolated from blood at on different days (30 June, 25 July, and 1 August 2014), while the first set of isolates from NPAs and induced sputum was detected on 18 and 19 August 2014, respectively. Similar information highlighted on the table that showed demographic detail of the infected individuals (Table $5)$.

Table 4. Bacterial growth result from screened health workers' hands.

\begin{tabular}{cl}
\hline Staff ID Code & Result \\
\hline A & Coagulase-negative staphylococci $\left(<20 \times 10^{5}\right.$ organisms $\left./ \mathrm{mL}\right)$ \\
B & Coagulase-negative staphylococci $\left(<20 \times 10^{5}\right.$ organisms $\left./ \mathrm{mL}\right)$ \\
C & Coagulase-negative staphylococci $\left(<20 \times 10^{5}\right.$ organisms $\left./ \mathrm{mL}\right)$ \\
D & No bacterial growth \\
E & No bacterial growth \\
F & Coagulase-negative staphylococci $\left(<20 \times 10^{5}\right.$ organisms $\left./ \mathrm{mL}\right)$ \\
$\mathrm{G}$ & No bacterial growth \\
$\mathrm{H}$ & Coagulase-negative staphylococci $\left(<20 \times 10^{5}\right.$ organisms $\left./ \mathrm{mL}\right)$ \\
$\mathrm{I}$ & Coagulase-negative staphylococci $\left(<20 \times 10^{5}\right.$ organisms $\left./ \mathrm{mL}\right)$ \\
$\mathrm{J}$ & Coagulase-negative staphylococci $\left(<20 \times 10^{5}\right.$ organisms $\left./ \mathrm{mL}\right)$ \\
$\mathrm{K}$ & No bacterial growth \\
$\mathrm{L}$ & No bacterial growth \\
$\mathrm{M}$ & No bacterial growth \\
$\mathrm{N}$ & Coagulase-negative staphylococci $\left(<20 \times 10^{5}\right.$ organisms $\left./ \mathrm{mL}\right)$ \\
$\mathrm{O}$ & No bacterial growth
\end{tabular}


Table 5. Demographic detail of patient whose sample yielded Serratia liquefaciens.

\begin{tabular}{|c|c|c|c|c|c|}
\hline Patient ID & Date of isolation & Age in months & Sex & Diagnosis & Sample type \\
\hline 1 & 30-Jun-10 & 4 & $\mathrm{~F}$ & Pneumonia & Blood \\
\hline 2 & 25-Jul-10 & 6 & M & Pneumonia & Blood \\
\hline 3 & 01-Aug-10 & 9 & M & Pneumonia & Blood \\
\hline 4 & 22-Aug-10 & 13 & M & Pneumonia & Blood \\
\hline 5 & 26-Aug-10 & 4 days & $\mathrm{F}$ & Pneumonia & Blood \\
\hline 6 & 31-Aug-10 & 10 & M & Pneumonia & Blood \\
\hline 7 & 03-Sep-10 & 6 & $\mathrm{~F}$ & Meningitis & Blood \\
\hline 8 & 06-Sep-10 & 9 & $\mathrm{~F}$ & Pneumonia & Blood \\
\hline 9 & 07-Sep-10 & 60 & M & Pneumonia & LA \\
\hline 1 & 07-Sep-10 & 21 & $\mathrm{~F}$ & Pneumonia & LA \\
\hline 11 & 11-Sep-10 & 3 & $\mathrm{~F}$ & Septicaemia & Blood \\
\hline 12 & 13-Sep-10 & 18 & M & Pneumonia & Blood \\
\hline 13 & 13-Sep-10 & 5 & $\mathrm{~F}$ & Pneumonia & Blood \\
\hline 14 & 14-Sep-10 & 11 & $\mathrm{~F}$ & Pneumonia & Blood \\
\hline 15 & 15-Sep-10 & 23 & $\mathrm{~F}$ & Pneumonia & LA \\
\hline 16 & 15 -Sep-10 & 3 days & $\mathrm{F}$ & Septicaemia & Blood \\
\hline 17 & 15-Sep-10 & 42 & M & Pneumonia & LA \\
\hline 18 & 15 -Sep-10 & 26 & M & Pneumonia & Blood \\
\hline 19 & 18-Aug-10 & 3 & $\mathrm{~F}$ & Pneumonia & NPA \\
\hline 20 & 18-Aug-10 & 14 & M & Pneumonia & NPA \\
\hline 21 & 18-Aug-10 & 7 & M & Pneumonia & NPA \\
\hline 22 & 19-Aug-10 & 24 & M & Pneumonia & NPA \\
\hline 23 & 19-Aug-10 & 10 & M & Pneumonia & IS \\
\hline 24 & 20-Aug-10 & 7 & $\mathrm{~F}$ & Pneumonia & NPA \\
\hline 25 & 20 -Aug-10 & 17 & M & Pneumonia & NPA \\
\hline 26 & 20-Aug-10 & 9 & M & Pneumonia & IS \\
\hline 27 & 23-Aug-10 & 58 & $\mathrm{~F}$ & Pneumonia & IS \\
\hline 28 & 23-Aug-10 & 9 & M & Pneumonia & NPA \\
\hline 29 & 23-Aug-10 & 8 & M & Pneumonia & NPA \\
\hline 30 & 23-Aug-10 & 58 & $\mathrm{~F}$ & Pneumonia & NPA \\
\hline 31 & 24-Aug-10 & 33 & M & Pneumonia & NPA \\
\hline 32 & 24-Aug-10 & 34 & M & Pneumonia & NPA \\
\hline 33 & 25-Aug-10 & 8 & M & Pneumonia & NPA \\
\hline 34 & 27-Aug-10 & 6 & M & Pneumonia & NPA \\
\hline 35 & 01-Sep-10 & 15 & M & Pneumonia & NPA \\
\hline 36 & 14-Sep-10 & 3 & $\mathrm{~F}$ & Pneumonia & NPA \\
\hline 37 & 14-Sep-10 & 17 & M & Pneumonia & IS \\
\hline 38 & 12-Sep-10 & 12 & M & Pneumonia & NPA \\
\hline 39 & 13-Sep-10 & 20 & M & Pneumonia & NPA \\
\hline 40 & 14-Sep-10 & 4 & M & Pneumonia & NPA \\
\hline 41 & 14-Sep-10 & 6 & M & Pneumonia & NPA \\
\hline 42 & $14-$ Sep-10 & 4 & M & Pneumonia & NPA \\
\hline 43 & 15 -Sep-10 & 13 & $\mathrm{M}$ & Pneumonia & NPA \\
\hline 44 & 16-Sep-10 & 6 & $\mathrm{~F}$ & Pneumonia & NPA \\
\hline
\end{tabular}

LA: lung aspirate; NPA: nasopharyngeal aspirate; IS: induced sputum. 
This investigation confirmed the reservoir for $S$. liquefaciens in saline preparations, infusion fluid, liquid medications (particularly multi-use vials/containers), inhalation fluid, and ventilation and mechanical equipment, as shown in table 2. Our findings are similar to those observed in previous studies $[16,28]$.

A number of corrective actions were taken to eradicate the spread of S. liquefaciens. We removed and destroyed contaminated saline, nebulizers, suction tubing, methylated spirit bottles, salbutamol solutions, and syringes. We disinfected all equipment, surfaces, oxygen concentrators, and nebulizing devices with $10 \%$ sodium hypochlorite. In addition, we autoclaved all heat-proof, reusable medical devices. In order to ensure complete eradication of $S$. liquefaciens, we re-sampled fresh normal saline, sabutamol fluid, sterilized equipment, and disinfected surfaces by swabbing for bacterial culture and isolation; the result obtained yielded no bacteria growth. Finally, we informed all staff about the likely source of the outbreak. Following the corrective actions, no further cases of S. liquefaciens have been detected in the MRC Basse laboratory.

We established preventive measures that included introduction of mandatory weekly general cleansing of the clinical area, and strongly encouraged strict hygiene such as washing of hands and arms with liquid soap and the use of cleansers containing 70\% alcohol before every procedure in which contamination may occur (e.g., before touching a patient, refilling saline reservoirs). We also introduced a strict policy that one syringe and one needle be used for any one patient receiving IV therapy, enforced the use of one nebulizing mask and chamber and one set of tubing per patient, and recommended that nebulizing procedures be performed in a separate identified area at the OPD or on the ward. In order to sustain the preventive measures, we introduced an infection control committee that comprises senior clinical and laboratory staff. The role of the committee is to address infection control issues and institute strategies to prevent reoccurrence of environmental microbial agents contaminating healthcare devices, equipment, and consumables.

\section{Conclusions}

Our study demonstrates that keen observation is important in order to identify outbreaks of HAI, and that HAIs and contamination can be avoided by adhering strictly to hygienic precautions. Our study also showed that $S$. liquefaciens, an environmental contaminant, has the potential to contaminate hospital consumables, devices, and equipment and ultimately contaminate and infect humans in a low-income country. We recommend strict aseptic procedure in the preparation of fluids for patient care, continuous cleansing and disinfecting of the healthcare environment, along with training and re-training of health workers. Also, we recommend that research to document the magnitude HAIs in low-income countries be encouraged. Thorough investigations will raise awareness among policymakers and strengthen political will to support initiatives that can prevent long stays in hospital that often stem from HAIs. In this way, unnecessary healthcare cost and unwarranted morbidity and mortality in healthcare facilities in low-income countries can be averted.

\section{Acknowledgements}

We thank Alhagie Konateh, Sampa Sanneh, and Sulayman Bah of MRC unit for their cooperation and technical support. Also, we are grateful to all MRC nurses at the Basse Health Center and MRC Basse laboratory staff for their immense technical support.

We express our profound gratitude to Medical Research Council Unit of The Gambia for providing us infrastructure and funding to do this study.

\section{Authors' contributions}

UNI conceived and designed the study. UNI, AK, ML, and JM performed the laboratory investigation. UNI and GAM wrote the manuscript.

\section{References}

1. Allegranzi B, Bagheri NS, Combescure C, Graafmans W, Attar H, Donaldson L, Pittet D (2011) Burden of endemic healthcare-associated infection in developing countries: systematic review and meta-analysis. Lancet 377: 228-241.

2. Nejad BS, Allengranzi B, Syed SB, Ellis B, Pittet D (2011) Health-care-associated infection in Africa: a systemic review. Bull World Health Organ 89: 757-765.

3. Naidu K, Nabose I, Ram S, Viney K, Graham SM, Bissel K (2014) A descriptive study of nosocomial infections in an adult intensive care unit in fiji: 2011-12. J Trop Med. 2014: Article ID 545160.

4. Morgan DJ, Rogawski DJ, Thom KA, Jonson JK, Perencevich EN, Shardell M, Leekha S, Harris AD (2012) Transfer of multidrug-resistant bacteria to healthcare workers' gloves and gowns after patient contact increases with environmental contamination. Crit Care Med 40: 1045-1051.

5. World Health Organization (2009) WHO Guidelines on Hand Hygiene in Health Care. Available: http://apps.who.int/medicinedocs/documents/s16320e/s16320 e.pdf. Accessed 13 April 2015.

6. Grimont FG and Patrick AD (2006) The Genus Serratia. Prokaryotes 6: 219-244.

7. Kim JH, Choi WH, Yun SW, Chae SA, Yoo BH (2010) An outbreak of serratia marcescens sepsis in a pediatric ward. Clin Pediatr 49: 1000-1002. 
8. Laupland KB, Parkins MD, Gregson DB, Church DL, Ross T, Pitout JD (2008) Population-based laboratory surveillance for Serratia species isolates in a large Canadian health region. Eur J Clin Microbiol Infect Dis 27: 89-95.

9. Stock I, Grueger T, Wiedemann B (2003) Natural antibiotic susceptibility of strains of Serratia marcescens and the $S$. liquefaciens complex: $S$. liquefaciens sensu stricto, $S$. proteamaculans and $S$. grimesii. Int J Antimicrob Agents 22: 35-47.

10. Serruys-Schoutens E, Rost F, Depre G (1984) A nosocomial epidemic of Serratia liquefaciens urinary tract infection after cystometry. Eur J Clin Microbiol 3: 316-317.

11. Mahlen SD (2011) Serratia infections: from military experiments to current practice. Clin Microbiol Rev 24: 755791.

12. Aydin SE, Erman Z, BilGin OC (2001) Investigations of Serratia liquefaciens Infection in Rainbow Trout. Turk J Vet Animal Science 25: 643-650.

13. Samonis G, Vouloumanou EK, Cristofaki M, Dimopoulou D, Maraki S, Trantafyllou E, Kofteridis DP, Falagas ME (2011) Serratia infection in a general hospital: Characteristics and outcomes. Eur J Clin Microbiol \& Infect Dis 30: 653-660.

14. Grohskopf LA, Roth VR, Feikin DR, Arduino MJ, Carson LA, Tokars JI, Holt SC, Jensen BJ (2001) Serratia liquefaciens bloodstream infections from contamination of epoetin alfa at a hemodialysis center. N Engl J Med 344: 1491-1497.

15. Dubouix A, Roques C, Segonds C, Segonds C, Jeannot MJ, Malavaud S, Daude S, Chabanon G, Marty N (2005) Epidemiological investigation of a Serratia liquefaciens outbreak in a neurosurgery department. J Hosp Infect 60: 8-13.

16. Harnett SJ, Allen KD, Macmillan RR (2001) Critical care unit outbreak of Serratia liquefaciens from contaminated pressure monitoring equipment. J Hosp Infect 47: 301-307.

17. Macias AE, Munoz JM, Bruckner DA, Galvan A, Rodriguez AB, Guerrero AB, Medina H, Gallaga JC, Cortes G (1999) Parenteral infusions bacterial contamination in a multiinstitutional survey in Mexico: considerations for nosocomial mortality. Am J Infect Control 27: 285-290.

18. Boulton FE, Chapman ST, Walsh TH (1998) Fatal reaction to transfusion of red-cell concentrate contaminated with Serratia liquefaciens. Transfus Med 8: 15-18.

19. Duncan KL, Ransley J, Elterman M (1994) Transfusiontransmitted Serratia liquefaciens from an autologous blood unit. Transfusion 34: 738-739.

20. European Centre for Ddisease Prevention and Control (2010) Annual Epidemiological Report on Communicable Disease in
Europe $2010 . \quad$ Available: http://ecdc.europa.eu/en/publications/Publications/1011_SUR Annual_Epidemiological_Report_on_Communicable_Disea ses_in_Europe.pdf. Accessed 17 September 2015.

21. Engelhart S, Saborowski F, Krakau M, Scherholz-Schlosser G, Heyer I, Exner I (2003) Severe Serratia liquefaciens sepsis following vitamin $\mathrm{C}$ infusion treatment by a naturopathic practitioner. J Clin Microbiol 41: 3986-3988.

22. Chuang TY, Chuang CP, Cheng HH, Hsueh PR (2007) Aortic valve infective endocarditis caused by Serratia liquefaciens. J Infect 54: e161-e163.

23. Waldermann F, Maucher OM, Buck A, Goerttler E (1987) Fistulous pyo-derma caused by Serratia liquefaciens. Hautarzt 38: 36-39.

24. Mossad SB (2000) The world's first case of Serratia liquefaciens intravascular catheter-related suppurative thrombophlebitis and native valve endocarditis. Clin Microbiol Infect 6: 559-560.

25. Arslan U, Erayman I, Kirdar S, Yuksekkaya S, Cimen O, Tuncer I, Bozdigan B (2010) Serratia marcescens sepsis outbreak in a neonatal intensive care unit. Pediatr Int 52: 208212.

26. Fitzgerald P, Drew JH, Kruszelnicki I (1984) Serratia: a problem in a neonatal nursery. Aust Paediat J 20: 205-207.

27. Engel HJ, Collignon PJ, Whiting PT. Kennedy KJ (2009) Serratia sp. bacteremia in Canberra, Australia: a populationbased study over 10 years. Eur J Clin Microbiol Infect Dis 28: 821-824.

28. Hurrell E, Kucerova E, Loughlin M, Caubilla-Barron J, Hilton A, Amstrong R, Smith C, Grant J, Shoo S, Forsythe S (2009) Neonatal enteral feeding tubes as loci for colonisation by members of the Enterobacteriaceae. BMC Infect Dis 9: 146.

\section{Corresponding author}

Usman Nurudeen Ikumapayi, MD

Department for Disease Control and Elimination

MRC Unit, Gambia

P.O. Box 273, Banjul

The Gambia, West Africa

Phone: 002209904956

Email: uikumapayi@mrc.gm

Conflict of interests: No conflict of interests is declared. 